\title{
Roll, roll, roll me away
}

W

hen Shelley Stoddart applied for a nursing position with the mobile eye care clinic run by CNIB, there was one job requirement she didn't understand: the need for an AZ license. So she called her father. "When he heard, he said: 'You're going to have to become a truck driver'."

Stoddart passed her tractor-trailer test and soon she was behind the wheel of a 48 -foot trailer hauling eye care equipment over 6000 kilometres of northern Ontario highways. She shared the semi with another nurse. Ophthalmologists from across Canada met them in 30 small communities along the route. With the help of a legion of volunteers, mostly from local Lions Clubs, the Eye Van team delivers care to about 5000 patients annually. With different staff, and a few different trucks, the unit has been making the rounds for the last 40 years.

It's one of the most established mobile clinics in the country, but it is only one example of the many different travelling health centres, including buses, vans, and even planes, delivering eye care, magnetic resonance imaging, dental care and mammography screening, that are offering a partial solution to a long-standing problem in Canada.

Most of Canada's vast territory is sparsely populated, and many of the roughly $19 \%$ of Canadians, or about six million people, living in those areas have difficulty accessing some forms of medical care. Roughly $14.6 \%$ of family physicians work in rural areas (https ://secure.cihi.ca/estore/productFamily .htm?locale=en\&pf=PFC1968), as do about $2.2 \%$ of specialists.

Judith Kulig, coauthor of Health in Rural Canada, says Canadians errantly assume they have equitable and guaranteed access to insured health services. "But the reality is, we don't."

That's a function of both having to drive long distances to obtain care and the unwillingness of many health professionals to work in rural or remote

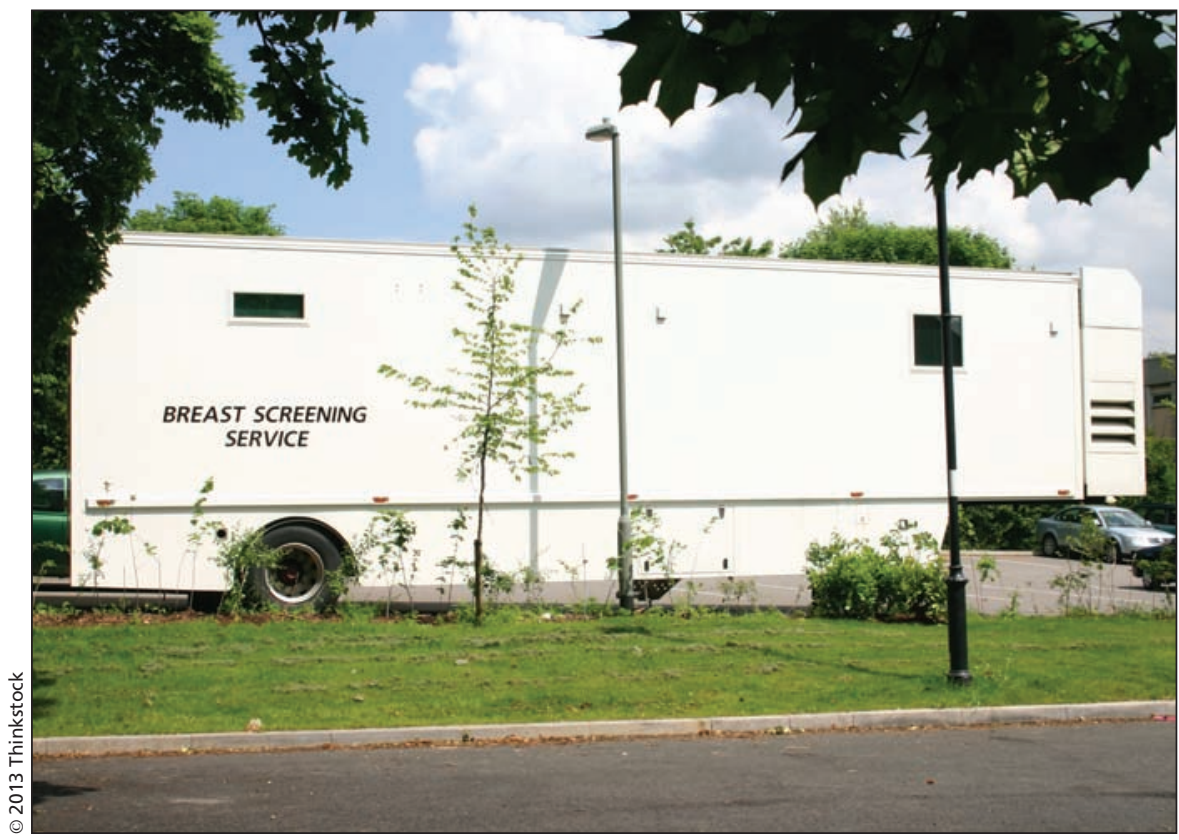

Mobile clinics are a niche solution to the gap in health services offered in rural and urban areas of Canada.

areas, she says. "We know they're not going to pick up and go to those places tomorrow and fall in love with them. So I think that you use that system [mobile clinics] and you make it as strong as you can."

Several types of travelling clinics have started up to serve remote areas across the country. People living in five northern Alberta towns have been able to receive a magnetic resonance imaging scan aboard a tractor-trailer since 2007. It now serves about 4200 people annually, says Mark Evans, spokesman for Alberta Health Services. The government also runs a small mobile dialysis unit that delivers treatment to 10 patients in the towns of Hinton and Whitecourt on alternating days of the week.

When people need emergency dental work in 26 isolated First Nations communities in northern Ontario, they have to fly to Sioux Lookout (roughly midway between Thunder Bay, Ont. and Winnipeg, Manitoba). For more routine procedures, Health Canada flies dentists and hygienists into the communities. In 2011, there were 78 visits from hygienists, and more than 6600 people had their teeth cleaned through the Sioux Lookout Zone Dental program.

In Nova Scotia, a Winnebago van began delivering mammography services in eastern parts of the province in 1994. The program was expanded to three vans but then reduced in December 2012 because the province increased the number of fixed mammography sites from just 1 to 11 . Theresa Foley, manager of the Nova Scotia Breast Screening Program, says one truck will continue to serve remote areas, because "no woman in the province should have to go more than 50 kilometres to get a mammogram." Similar mobile mammography clinics operate out of trucks and buses in several other provinces, as part of provincial breast screening programs.

While such clinics are typically run through government or large health care organizations, in Newfoundland and Labrador, Dr. Roxanne Cooper decided to start one on her own. As a member of a committee seeking a means of boost- 
ing the number of women in the province who got cervical screenings, Cooper reasoned that a mobile Pap test clinic could help. To that end, she obtained a provincial grant and her husband, a carpenter, converted a camping trailer into a clinic on wheels. Together, they visited 10 communities across Newfoundland, from Gander to the small fishing town of Trepassey in the summer and fall of 2010.

"Our goal was to hit those women who hadn't been screened in years," she says. "A really high proportion of the people I saw had not had a pap test in 10 years or more." Cooper adds that many older women aren't aware they need to get regular tests, often have to drive at least an hour to get care or aren't comfortable seeing a male doctor in their home town. While she hasn't run the clinic since the 2010 tour, Cooper plans to eventually get the Pap test trailer back on the road.

While travelling vans are often focused on providing one procedure or service, they've occasionally made broader discoveries, as was the case with the eye van when it treated a man and discovered that he had a brain tumour, notes Dr. Janette Lyndley, who has been doing stints on the van for 25 years.

In the case of the Eye Van, it has even expanded its operations, partnering with the Northern Diabetes Health Network to provide education and testing for the disease.

But not everyone is convinced that mobile clinics are the solution, including Dr. John Wootton, former head of the now-defunct federal Office of Rural Health. While there's a benefit to bringing care to patients, mobile clinics are an incomplete solution, says Wootton, now a family physician in Shawville, Quebec. "In general I think, they don't last very long."

They can also be an expensive form of care, since vehicles and sensitive equipment take a beating on the road. The Eye Van kept its last slit lamp for about half the time it would last in a regular office. Lasers, which cost about $\$ 100000$, only last about three or four years. However, Lyndley points out that the cost of operating the eye van $\$ 650000$ to $\$ 700000$ per year - likely would not surpass the cost of travel for all their patients to have their eyes checked annually at larger centres.

For some procedures, telehealth options may complement the travelling clinic. CNIB has started teleophthalmology pilot projects in several communities. In British Columbia, mobile diabetes telemedicine clinics serve First Nations communities throughout the province, run by the Carrier Sekani Family Services in the north and the Seabird Island Indian Band in the south. Vans or planes visit communities to screen for diabetes, which includes photographing patients' eyes and sending the images to a specialist in Vancouver, before giving the patient a diagnosis.

But Wootton maintains that neither the mobile clinics nor telehealth are the solution to closing the gap in services offered in rural and urban areas. "Like telemedicine, mobile clinics are a very niche solution. They work in some places where the economics make sense, and where the technology can survive the bumpy roads." - Julia Sisler, Toronto, Ont.

CMAJ 2013. DOI:10.1503/cmaj.109-4367 